12 weeks. No change in medication was allowed during this time. ANS function and balance were determined by quantification of the variability of the inter-beat interval detected with the Polar $810 \mathrm{i}$ heart rate monitor system. Frequency domain analyses were used for quantification, including $\mathrm{LF}\left(\mathrm{ms}^{2}\right)$ - indicating mainly sympathetic influence, HF $\left(\mathrm{ms}^{2}\right)$ - indicating parasympathetic influence, and LF/HF indicator of autonomic balance.

Results: The two groups matched regarding baseline demographic data (age, sex, disease activity, disease duration). Due to small sample sizes and variables not following a normal distribution, non-parametric Mann Whitney $U$ analyses were performed on the heart rate variability parameters. Comparing posture change (i.e. standing value minus supine value) from pre- to post intervention, all frequency domain parameters changed as anticipated (i.e. vagal withdrawal and increased sympathetic influence) for the RAE group. For the RAC group the measurements deteriorated.

LF $\left(\mathrm{ms}^{2}\right)$ : RAE -1.03 to 22.03 (stronger sympathetic influence); RAC 43.45 to 31.21 (weaker sympathetic influence)

HF (ms ${ }^{2}$ ): RAE -24.03 to -33.34 (better vagal withdrawal); RAC -191.7 to -114.1 (less vagal withdrawal)

LF/HF: RAE 10.57 to 15.04 ; RAC 2.9 to 7.6

Conclusions: From these preliminary results it appear that exercise may indeed improve autonomic function in RA patients, in such a way that posture change will not be an added burden for falls in an already otherwise compromised population. Disclosure of Interest: None declared

DOI: 10.1136/annrheumdis-2018-eular.6261

\section{FRI0683 INVESTIGATION OF THE RELATIONSHIP BETWEEN PLANTAR PRESSURE DISTRIBUTION AND LUMBAR MULTIFIDUS MUSCLE THICKNESS}

C. Karartı ${ }^{1}$, S. Bilgin ${ }^{2}$, Y. Dadalı ${ }^{3}$, E. Dülger ${ }^{2}$, B. Büyükturan ${ }^{1}$, Ö. Büyükturan ${ }^{1} .{ }^{1} A h i$ Evran University, Department of Physiotherapy and Rehabilitation, Kırşehir,

${ }^{2}$ Department of Physiotherapy and Rehabilitation, Hacettepe University Institute of Health Sciences, Ankara, ${ }^{3}$ Ahi Evran University, Department of Radiology, Kırşehir, Turkey

Background: Lumbar multifidus is a muscle which is responsible for lumbopelvic stability primarily. Foot-ankle posture and function disorders affecting the lumbopelvic region muscles and biomechanics, cause increased stress in the lumbopelvic region and may cause low back pain in many studies $(1,2,3)$. However, it is not known whether the lumbar multifidus muscle is affected by this condition $(4,5)$

Objectives: Plantar pressure distribution can change due to foot-ankle postural disorders. Our aim is to examine whether the plantar pressure distribution affects the lumbar multifidus muscle thickness.

Methods: 40 healthy young adults aged 18 to 25 years were included in the study. Static and dynamic pedobarographic assessments were performed to determine the plantar pressure distribution, on a $3 \times 1$ meter sensored walking platform with the DIASU Digital Analysis System ${ }^{\circledR}$. Peak pressures $\left(\mathrm{N} / \mathrm{cm}^{2}\right)$ of 9 zones of the foot (medial of heel, lateral of foot, 5 metatarsal, thumb and 2.3.4 and 5. digits) were recorded. Ultrasonographic imaging was used to assess lumbar multifidus muscle thickness.

Results: There was statistically significant correlation between lumbar multifidus muscle thickness and peak pressure medial of heel and 1. metatarsal bone in static pedobarographic analysis $(p<0.05)$. As the peak pressure on the medial part of foot increased, $\mathrm{m}$. lumbar multifidus muscle thickness was reduced. There was statistically significant correlation between lumbar multifidus muscle thickness and pressure medial of heel and 2.3.4. and 5. digits in dynamic pedobarographic analysis $(p<0.05)$. As the peak pressure on the medial part of foot increased, m. lumbar multifidus muscle thickness was reduced.

Conclusions: Our results show that plantar pressure distribution affected lumbar multifidus muscle thickness. Based on these results, the lumbopelvic region and foot posture should be considered together in therapeutic interventions.

\section{REFERENCES:}

1. Bird AR, Payne CB. Foot function and low back pain. Foot 1999;9(4):17580

2. Botte RR. An interpretation of the pronation syndrome and foot types of patients with low back pain. J Am Podiatry Assoc 1981;71(5):243-53.

3. Barwick A, Smith J, Chuter V. The relationship between foot motion and lumbopelvic-hip function: a review of the literature. Foot (Edinb) 2012;22 (3):224-31.

4. Brantingham JW, Adams KJ, Cooley JR, Globe D, Globe G. A single-blind pilot study to determine risk and association between navicular drop, calcaneal eversion and low back pain. J Manipulative Physiol Ther 2007;30 (5):380-5

5. Fourchet F, Kelly L, Horobeanu C, Loepelt H, Taiar R, Millet G. High-intensity running and plantar-flexor fatigability and plantar-pressure distribution in adolescent runners. J Athl Train 2015;50(2):117-25.
Disclosure of Interest: None declared

DOI: 10.1136/annrheumdis-2018-eular.6363

\section{FRI0684 \\ EFFICIENCY OF COMPLEX REHABILITATION PROGRAM IN PATIENTS WITH RHEUMATOID ARTHRITIS RECEIVING ABATACEPT}

E. Orlova ${ }^{1}$, D. Karateev ${ }^{2}$, A. Kochetkov ${ }^{1} .{ }^{1}$ Department of Rehabilitation Medicine, Federal Medical Biological Agency, ${ }^{2} 1$ st Department of internal medicine, Moscow Regional Research and Clinical Institute ("MONIKI"), Moscow, Russian Federation

Background: Rehabilitation techniques (physical exercises, physiotherapy occupational therapy, patient education) help to manage rheumatoid arthritis (RA) in addition to drug treatment [1-4].

Objectives: To evaluate the efficiency of 12-month complex rehabilitation program in patients with $\mathrm{RA}$ receiving abatacept.

Methods: 50 patients with RA ( $94 \%$ females, $72 \%$ with moderate disease activity by DAS28, age of 18 to 57 years, disease duration of 10 months to 12 years) were included and randomized into 2 groups. All patients received abatacept (intravenously $10 \mathrm{mg} / \mathrm{kg}$ (mean $750 \mathrm{mg}$ ) once every 4 weeks or subcutaneously $125 \mathrm{mg}$ once a week) with methotrexate $20-25 \mathrm{mg}$ per week. 28 study group patients underwent 12-months complex rehabilitation program: laser therapy of 12 to 16 min (infrared low intensity laser radiation, wavelength of 0,89 micrometers, pulse frequency of 1000 to $1500 \mathrm{~Hz}$ ) for hand, knee, ankle, shoulder and elbow joints, 3 courses for 14 sessions with a mean interval of 3,2 months; 45-min dynamic exercises using gym apparatus Enraf-Nonius under the supervision of a trainer 3 times a week; 45-min exercises for hands 3 times a week; 45-min occupational therapy (joint protection strategies, use of assistive devices and adaptive equipment), 10 sessions; wrist, ankle and knee orthoses, orthopedic insoles; education program (4 daily 90-min studies). 22 patients received only drug therapy (control). Tender and swollen joint count, erythrocyte sedimentation rate (ESR), C-reactive protein (CRP), joint pain on 100-mm VAS, DAS28, HAQ, RAPID3, hand grip strength, the average powers of knee extension and ankle flexion by EN-TreeM movement analysis were evaluated at baseline and at 12 months.

Results: After 12 month in the study group tender joint count decreased by $69,3 \%$ ( $»<0,01$ ), swollen joint count - by $66,2 \%$ ( $»<0,01)$, ESR - by $63,7 \%$ (»<0,01), CRP - by $58,5 \%(»<0,01)$, pain on VAS - by $82,3 \%(»<0,01)$, DAS28 by $39,6 \%(\triangle D A S 28=2,89 \pm 0,99, »<0,05), H A Q-$ by $72,2 \%(\triangle H A Q=1,73 \pm 0,44$ $»<0,01)$, RAPID3 - by $78,3 \%$ ( $\triangle$ RAPID3 $=8,45 \pm 0,85, »<0,01)$. The grip strength of a more affected hand enhanced by $57,1 \%(»<0,01)$, of a less affected - by $46,2 \%(»<0,05)$. The average extension power of a weaker knee increased by $72,1 \%(»<0,01)$, of a stronger - by $65,8 \%(»<0,01)$. The average flexion power of a more affected ankle joint elevated by $48,9 \%(»<0,05)$, of a less affected - by $69,4 \%("<0,01)$. In the study group there were statistically significant differences from the control group in the most parameters $(»<0,05)$, excluding CRP, ESR DAS28 and the average flexion power of a more affected ankle joint $(">0,05)$ After 12-months in the study group there was significantly more frequently a good response to treatment according to the EULAR criteria (DAS 28$)(85,7 \%$ vs $63,6 \%$ in the control group, »<0,05).

Conclusions: 12 -month complex rehabilitation program relieves pain, improves quality of life, functional status, motion activity and helps to control disease activity in patients with RA receiving abatacept.

\section{REFERENCES:}

[1] Forestier R, et al. Joint Bone Spine 2009;76(6):691-8.

[2] Hurkmans EJ, et al. Acta Reumatol Port 2011;36(2):146-58.

[3] Vliet Vlieland TPM. Best Pract Res Clin Rheumatol 2009;23(1):103-16.

[4] Vliet Vlieland TPM, van den Ende CH. Curr Opin Rheumatol 2011;23 (3):259-64.

Disclosure of Interest: None declared DOI: 10.1136/annrheumdis-2018-eular.6278

\section{FRI0685 HAND FUNCTIONS ARE AFFECTED DEPENDING ON THE CURVE PATTERN IN IDIOPATHIC SCOLIOSIS}

G. Yagci ${ }^{1}$, D. A. Ozcan ${ }^{1}$, C. Ayhan ${ }^{1}$, Y. Yakut ${ }^{2} .{ }^{1}$ Physiotherapy and Rehabilitation, Hacettepe University, Ankara, ${ }^{2}$ Physiotherapy and Rehabilitation, Hasan Kalyoncu University, Gaziantep, Turkey

Background: Idiopathic scoliosis (IS) is a three-dimensional deformity and causes postural distortions in head, trunk, scapular region and upper extremities. Hand functions have not been evaluated in relation to lateral curvature of the spine in IS previously. There is a need to evaluate possible changes in hand functions with scoliotic curve in idiopathic scoliosis. 